\title{
LA CONSTITUCION DE 1979 Y EL DERECHO DEL TRABAJO
}

Carlos Blancas Bustamante

La Constitución Política aprobada en 1979 por la Asamblea Constituyente, que nos rige plenamente desde el 28 de Julio de 1980, reconoce al trabajo como hecho social y económico y al Derecho del Trabajo un rol de gran importancia dentro del Estado peruano y su ordenamiento juridico y social. En este sentido, la Constitución de 1979 otorga a la materia laboral un tratamiento amplio y variado, superando largamente a las otras dos constituciones del presente siglo, las de 1920 y 1933, que abordaron el tema de manera más o menos dispersa y genérica.

Nuestra actual Constitución, dedica al trabajo no sólo integramente el Capítulo $\mathrm{V}$ del Título Primero, título consagrado a los derechos fundamentales de la persona, sino que en otros titulos y capítulos del texto, incluyendo en el recuento al propio Preámbulo, se hallan conceptos y definiciones que se sustentan en el trabajo. Asi, por ejemplo, el segundo párrafo del Preámbulo declara: "Que el trabajo es deber y derecho de todos los hombres y representa la base del bienestar nacional".

La abundancia de normas referentes al trabajo hace necesario abordar, con el mayor detenimiento, el estudio de la significación que encierra, tanto para el Derecho Constitucional como 
para el Derecho del Trabajo, la presencia en nuestra Constitución de declaraciones, principios y derechos sobre materia laboral.

\section{EL CONSTITUCIONALISMO SOCIAL Y EL DERECHO DEL TRABAJO}

\section{A. Perspectiva histórica}

La presencia en el texto constitucional de principios y normas sobre el trabajo, como hecho social y como objeto específico del derecho del trabajo, constituye una de las manifestaciones tipicas de aquel fenómeno jurid:co-constitucional conocido como el "constitucionalismo social". El "constitucionalismo social" representa, en acertada descripción de Tissembaum, "... un proceso de penetración del derecho laboral y del derecho social en el derecho constitucional para caracterizarlos en sus fines, y luego éste, con el impulio consiguiente, se proyecta a su vez en aquéllos para asignarles la firme orientación institucional de sus postulados rectores, hacia el ordenamiento legal respectivo" (1). Por su parte. Alonso Garcia precisa el sentido, al menos inicial, y ciertamente principal, que tiene el "constitucionalismo social": "Entre estos derechos sociales, los que derivan del trabajo como valor fundamental de la vida social ocupan un lugar importante, y al ser el Derecho laboral el que se ocupa de la regulación de las relaciones nacidas del trabajo, hace que, cuando se habla de incorporación de las cláusulas laborales a los textos constitucionales, se intente definir la caracterización general del movimiento calificándolo como constitucionalización del Derecho del Trabajo" (2).

De este modo, el constitucionalismo social aparece, en primer término, como "constitucionalización del Derecho del Trabajo", aun cuando más tarde comprenderá otros derechos sociales distintos a los específicamente laborales. En el derecho mexicano, el

(1) TISSEMBALM, Mariano R. "La Constitucionalización del Derecho del Trabajo", en Tratado de Derecho del Trabajo, dirigido por Mario Deveali, La Ley, Buenos Aires, 1971, Tomo I, p. 178.

(2) ALONSO GARCIA, Manuel, Curso de Derecho del Trabajo, Ariel, Barcelona, 1975. p. 158. 
fenómeno comprendió, desde el primer momento, al derecho del trabajo y al derecho agrario (3).

Precisamente, se reconoce por lo general como punto de partida de esta corriente, a la Constitución Mexicana de 1917, a la que se atribuye el mérito de haber sido la primera en consagrar, en su célebre y extenso Articulo 123, un conjunto de normas y derechos fundamentales relativos al trabajo. Dos años más tarde, en 1919, la Constitución de la naciente República Alemana, también conocida como "Constitución de Weimar", incluyó entre sus normas algunas de gran trascendencia referentes a la seguridad social, el derecho de coalición, la unificación del derecho obrero, la formación de consejos obreros en las fábricas, etc. Años después. la República Española proclamaba en su Constitución de 1931 que "España es una República democrática de trabajadores de todas las clases".

Esta corriente que fue ganando impulso paulatinamente, bajo la presión de grandes acontecimientos sociales, económicos y políticos, se extendió notablemente después de la segunda guerra mundial, alcanzando a algunas grandes constituciones europeas. Entre ellas, debemos mencionar la Constitución Francesa de 1946. cuyo preámbulo enumera un conjunto de principios y derechos de naturaleza laboral que siguen vigentes bajo la Constitución de 1958, la Constitución Italiana de 1947 que toca ampliamente el tema en sus Disposiciones Generales y en el Título III de su Parte I y más recientemente las Constituciones española de 1978 y la portuguesa de 1976. También en América Latina se difundió, durănte el presente siglo y más acentuadamente luego de la segunda guerra mundial, la corrente de constitucionalización del Derecho del Trabajo, encontrando expresión en numerosos textos constitucionales. Podemos citar, entre los más recientes, la Constitución Venezolana de 1961, que destina el Capitulo IV del Título III a los "Derechos Sociales" y, asimismo, incluye referencias al trabajo en el preámbulo y en el capítulo relativo a deberes de los venezolanos; la Constitución argent'na, que al ser reformada en

(3) Ver la Constitución Politica de los Estados Unidos Mexicanos, Articulo 27. 
1957, incluyó en su nuevo Artículo 14 una enumeración bastante extensa y consistente de normas y derechos laborales; la Constitución Colombiana, que reconoce al trabajo como "obligación social" y le asigna la protección del Estado y que, igualmente, garantiza el derecho de huelga, en sus Articulos 17 y 18; y naturalmente, la Peruana de 1979.

Sin embargo, entre nosotros, la Const tución de 1979 encuentra antecedentes en las dos constituciones anteriores que el Perú ha tenido en este siglo. Puede considerarse que la Constitución de 1920. elaborada y promulgada al inicio de la "Patria Nueva", representa, aunque tímidamente, la presencia del constitucionalismo social en el Perú. Dicha Constiución incluyó en su texto un Título IV denominado Garantias Sociales en el que reconoció algunos dereches laborales. El artículo 47 impuso al Estado la obligación de legislar sobre la organización y la seguridad del trabajo industrial y sobre las garantías en él de la vida, la salud y la higiene. Igualmente, estableció que la ley fijaría las condiciones del trabajo, los salarios mínimos y la indemnización de los accidentes de trabajo, que consideró obligatoria. El artículo 48 estableció el arbitraje obligitor:o para los conflictos entre el Capital y el Trabajo, y el Articulo 49 remitió a la ley la función de organizar los Tribunales de conciliación y arbitraje que debian resolver aquellos conflictos, asi como los requisitos y condiciones para dar efecto obligatorio a sus fallos. Cabe, también, mencionar el Artículo 56 que as gnó al Estado la obligación de fomentar las instituciones de previsión y solidaridad social, asi como otras instituciones, cntre cllas cooperativas de producción y consumo, "que tengan por objeto mejora: las condiciones de las clases populares".

La Constitución de 1933 mantuvo y, en cierto grado, acentuó, esta tenćencia a constitucicnalizar les derechos sociales, principalmente los derechos laborales. Asi, en su Título II, Capitulo I, consagrado a las Garantias Nacionales y Sociales impuso al Estado, en el articulo 43, la obligación de legislar sobre el contrato colectivo de rrabajo, y en su artículo 44 prohibió incluir en el contrato de trabajo toda estipulación que restrinja el ejercicio de los derechos civiles, políticos y sociales. El articulo 45, bastante avanzado para su época, señalaba "El Estado favorecerá un régimen de participación de los empleados y trabajadores en los beneficios 
de las empresas..." y agregaba la obligación del Estado de legislar sobre las relaciones entre los trabajadores y las empresas y sobre "la defensa de los empleados y trabajadores en general". El artículo 46, a su vez, remitió a la legislación la regulación de la organización y segur:dad del trabajo industrial, la protección de la vida y la salud en el trabajo, la higiene, las condiciones máximas de trabajo, la indemnización por tiempo de servicios y por accidentes de trabajo y los salarios minimos. Finalmente, el articulo 48 se refirió al establecimiento por ley de un régimen de previsión de las consecuencias económicas de la desocupación, edad, enfermedad, invalidez y muerte, y al fomento de las instituciones de sol:daridad y otras similares.

\section{B. Del Estado Liberal al Estado Social}

La constitucionalización del Derecho del Trabajo y, en general, el constitucionalismo social, están unidos o, para ser más exactos, forman parte de un proceso politico, social y económico más vasto y profundo: la transformación del estado liberal en estado social o democracia social.

Este proceso es la consecuencia de una serie muy amplia de factores, pero entre ellos, debe mencionarse, de un lado, la evolución y desarrollo de la técnica y la economia y, del otro, el surgimiento de profundas exigencias sociales y de movimientos politicos y sindicales que expresan la creciente presencia en el Estado de una nueva clase social que disputa a la burguesia su hegemonia: la clase trabajadora. El proceso señalado lleva a profundos cambios en la concepción teórica y las funciones concretas del estado tradicional, que lo van transformando en el denominado Estado Social. Los rasgos fundamentales de este cambio son descritos con gran precisión por Garcia Pelayo: "...mientras que el Estado tradicional se sustentaba en la justicia conmutativa, el Estado Social se sustenta en la justicia distributiva; mientras que el primero asignaba derechos $\sin$ mención de contenido, el segundo distribuye bienes juridicos de contenido material... mientras que el uno se limitaba a asegurar la justicia legal formal, el otro se extiende a la justicia legal material... Alli se trataba de un Estado cuya :dea se realiza por la inhibición, aqui se trata de un Estado que se realiza por su acción en forma de prestaciones so- 
ciales, dirección económica y distribución del producto nacional" (4).

Nuestra actual Constitución pretende insertarse en esta corriente, como se desprende del contenido de su articulo 79 , que define al Perí como "República democrática y social". Comentando esta disposición hemos sostenido que "Si bien se trata de una declaración general, de alcance político-social antes que estrictamente juridica, ella impone al Estado peruano una orientación inequivoca que lo obligará a establecer politicas, invertir recursos y crear servicios que efectivamente permitan el ejercicio de los derechos sociales y el logro del bienestar, el desarrollo y la eliminación de toda estructura de explotación" (5).

Si bien la idea del Estado Social inspira diversas normas de las Constituciones que se basan en dicha concepción, existen, a nuesiro juicio, algunas declaraciones o definiciones de carácter general que suelen aparecer en aquellos textos y que pretenden inspirar el conjunto de sus normas. Varias de aquellas declaraciones fundamentales están directamente referidas al trabajo, como podemos apreciarlo claramente en la Constitución de 1979. Ellas son, principalmente, las siguientes: 1) el trabajo como fundamento del Estado, 2) el trabajo como fundamento del régimen económico, y, 3) el trabajo como derecho y como deber social.

1) La idea del trabajo como fundamento del Estado tiene su expresión más nítida en el artículo 79 , que está consagrado a definir la forma del Estado peruano. Dicho artículo señala lo siguiente: "El Perú es una República democrática y social, independiente y soberana, basada en el trabajo. Su gobierno es unitario, represcntativo y descentralizado".

Dicha definición, que reviste un carácter fundamental en orden de determinar la orientación del Estado peruano, posee al-

(4) GARCIA-PELAYO, Manuel... Las transformaciones del Estado contemporáneo. Alianza Universidad, Madrid 1977, pp. 26-27.

(5) BLANCAS BUSTAMANTE, Carlos... El Estado y la Constitución de 1979, en Derecho, Programa de Derecho de la Universidad Católica, Lima, 1981, No 35, p. 10. 
gunos antecedentes importantes en la trayectoria del constitucionalismo social. Fórmula similar apareció por primera vez en la Constitución de la República Española de 1931 que afirmó en su artículo 1: "España es una República democrática de trabajadores de toda clase, que se organiza en régimen de libertad y justicia" (6). Muchos años después, la Constitución Italiana, promulgada en 1947, estableció en su Articulo Primero: "Italia es una República democrática, fundada sobre el trabajo".

Refiriéndose a la Constitución Italiana y luego de analizar los fundamentos y alcances de su articulo primero, Tissembaum sostiene que... "debemos inferir que el fundamento o espíritu del texto de la disposición mencionada no es otro que el de la revaloración jurídico-politica del trabajo, sin asignarle a este concepto un sentido clasista" (7).

La concepción del trabajo como un valor fundamental en la definición del Estado, posee una significación muy profunda pcrque implica un cambio sustancial en la forma de concebir el Estado. Bajo el liberalismo, el Estado tenia como fundamento esencial el valor de la "libertad", a cuya realización y protección debia consagrar sus mejores esfuerzos. Más aún, el concepto de libertad individual sirve como frontera para demarcar el ámbito de acción del Estado, que está subordinado a ella. Anota, por ello Schmitt que ". . la esfera de libertad del individuo se supone como un dato anterior al Estado, quedando la libertad del individuo ilimitada en principio, mientras que la facultad del Estado para invadirla es limitada en principio" (8).

Pero, la libertad del liberalismo es la libertad burguesa, concebida desde una perspectiva individualista, que recorta la noción integral de la persona humana y mutila, igualmente, la idea de sociedad. La "cuestión social", engendrada por el capitalismo, y muchas otras realidades semejantes, entre ellas la de nuestro propio subdesarrollo, han demostrado suficientemente las carencias de

(6) TISSEMBAUM, Mariano R. ... Op. cit. p. 183.

(7) IBIDEM, p. 184 .

(8) SCHMIT"T, Carl..., Teoria de la Constitución, México, Editora Nacional, 1966, p. 147. 
este concepto de libertad como basamento sólido para un orden social justo. Por ello, Tissembaum señala certeramente que: "La libertad que constituyó uno de los primeros planteos que inspiraron el constitucionalismo, no fue suficiente de por si para afirmar los derechos humanos en modo de consolidar su eficacia. Necesitó del complemento necesario para asegurar la posibilidad de hacerla efectiva, en la plenitud de su significado, o sea con dignidad" (9). $Y$, más adelante agrega: "Y el trabajo que antes se hallaba subestimado como actividad profesional humana, adquirió la jerarquia de un derecho que se consustanció con los otros esenciales de la vida humana, en modo equivalente al de la libertad" (10).

Asi pues, se enriquece la idea de la persona y la noción misma del Estado cuando, junto a la libertad, se afirma el trabajo como valor social fundamental, porque ello implica reconocer que el hombre se realiza a través de ambos valores y, que es función o deber del Estado tutelarlos conjuntamente, creando el ordenamiento social y económico que permita su plena manifestación.

En nuestro texto constitucional, la definición contenida en el articulo 79 guarda directa relación con los "deberes primordiaies" del Estado señalados en el artículo 80 , entre los cuales se mencionan los siguientes: ..." promover el bienestar general basado en la justicia y en el desarrollo integral y equilibrado del pais, y eliminar toda forma de explotación del hombre por el hombre y del hombre por el Estado".

Comentando estas disposiciones, Rubio y Bernales, anotan que "La consecuencia lógica de esta norma, unida al principio dci trabajo como fundamento de la República, es revalorizar pleramente al trabajador en una sociedad donde el individuo y las formas de explotación capitalista, no avasallen a las mayorias nacionales" (11).

(9) TISSEMBAUM, Mariano R. ... Op. cit. p. 179.

(10) Loc. cit.

(11) RUBIO, Marcial y BERNA $A_{-}^{-} E S$, Enrique, Perú: Constitución Sociedad Politica, DESCO, Lima 1981. p. 279. 
Creemos que la afirmación de los autores citados es rigurosamente correcta porque carecería de sent:do exaltar la noción dei trabajo, en abstracto, y no traducir ese culto en medidas concretas en beneficio del trabajador, para librarlo de cualquier situación en la que resulte, en la práctica, objeto de explotación. De este modo, revalorizar el trabajo implica, necesariamente, un compromiso del Estado para crear las condiciones soc'ales mininas que reconozcan al trabajo el destacado rol que le asigna la Constitución del Perú. En tal sentido, la definición del artículo 79 representa un principio rector para la totalidad de la vida económica y social y no sólo para las relaciones laborales.

2) Como una consecuencia de lo anterior, el trabajo aparece, también, en nuestra Constitución de 1979. como valor fundamental en relación al régimen económico. El artículo 110 reza así, en su primer párrafo: "El régimen económico de la Repúhlica se fundamenta en principios de justicia social orientados a la dignificación del trabajo como fuente principal de riqueza y como medio de realización de la persona humana". Asimismo, el articulo 42, correspondiente al capítulo Del Trabajo, señala en su primera frase que "El Estado reconoce al trabajo como fuente principal de la riqueza".

La relación entre el trabajo, como actividad productiva y creadora, y la economía es evidente, por lo que la Constitución se limita a reconocer el hecho, pero agregando, y esto es lo importante, su valoración de lo que significa el trabajo en la economia al concebirlo como "la fuente principal de la riqueza". Como tal, ins demás factores o elementos de la producción deben entenderse subordinados al factor trabajo. De otro lado, el mismo artículo 110 , define al trabajo como "medio de realización de la persona humana", con lo que añade a su importante función económica, la valoración ética a que se refiere Juan Pablo II cuando sostiene en "Laborem Exercens": El trabajo es un bien del hombre -- es un bien de su humanidad-, porque mediante el trabaio el hombre no sólo transforma la naturaleza adaptándola a lits propias necesidades sino que se realiza a si mismo como hombre, es más, en un cierto sentido "se hace más hombre" (12).

(12) Juan Pablo II. Enciclica Laborem Exercens. Editorial Sa'esiana. Lima, 1981 , p. 35 . 
La cuestión esencial con relación a este punto es determinar el grado de coherencia existente entre esta declaración de carácter general sobre el régimen económico y las normas que configuran el conjunto de dicho régimen. A este respecto, se ha destacado la contradicción de fondo que existe entre la afirmación del trabajo como fuente principal de la riqueza y medio de realización de la persona y la vigencia e, inclusive, consolidación de una economía capitalista, basada en el mercado y la propiedad privada de los medios de producción, como lo establece la Constitución. Para Rubio y Bernales “...cuando el artículo 110 es enfrentado a los tres principios básicos del régimen económico; cuando frente a ellos se enarbola una liberalización del concepto de propiedad; cuando no se asegura el empleo ni se da valor real apropiado al salario; cuando se posterga el rol de la planificación del desarrollo, dificilmente se puede decir que hay coincidencia entre la declaración general y las normas concretas" (13).

Por su parte, Ruiz-Eldredge sostiene: "No obstante, esta declaración de principios no se ha seguido en las normas de los capitulos siguientes sobre Recursos Naturales, Propiedad y Empresas y Régimen Agrario..." (14).

Por más que la Constitución tilde de "social" a la economia de mercado - usando un lenguaje neo-liberal-_ y reconozca como expresiones de la primacia del factor trabajo la existencia de empresas autogestionarias y cooperativas, es ev:dente que el régimen económico está presidido, en su normatividad especifica, por criterios capitalistas, con lo cual las posibilidades de llevar a la práctica los enunc'ados doctrinarios del artículo 110 son virtualmente minimas o simplemente nulas.

3) Nuestra actual Constitución, a diferencia de la Constitución de 1933, proclama el derecho al trabajo y, correlativamente, el deber de trabajar. Lo dice así la segunda frase del artículo

(13) RUBIO, Marcial... BERNALES, Enrique. Op. cit., p. 600.

(14) RUIZ ELDREDGE, Alberto... La Constitución comentada, Editora Atlántida, Lima, 1980, p. 177. 
42: "El trabajo es un derecho y un deber social". Lo señala, igualmente, el Preámbulo de la Constitución en su párrafo segundo, acápite segundo, cuando afirma "Que el trabajo es deber y derecho de todos los hombres y representa la base del bienestar nacional". Lo sostiene, asimismo, el articulo 76: "Todos contribuyen al bienestar general y a la realización de su propia personalidad mediante su trabajo como deber personal y social".

El derecho al trabajo y el deber de trabajar configuran dos principios o, si se quiere, dos aspectos de un mismo principio, que integran el patrimonio característico del constitucionalismo social. La Constitución Mexicana en su artículo 123 establece en el primer párrafo que "Toda persona tiene derecho al trabajo digno y socialmente útil". Por su parte la Constitución Alemana de 1919 (de Weimar) consignó en el artículo 163 lo siguiente: "Todo alemán tiene, sin perjuicio de su libertad personal, el deber moral de utiilzar sus fuerzas intelectuales y fís'cas conforme al interés de la colectividad". Como vimos en el apartado A del presente capitulo, varias de las más importantes y recientes Constituciones zuropeas y latinoamericanas proclaman, con diverso énfasis y expresión, similares principios.

Estos principios constituyen un aporte del constitucionalismo social en la medida que complementan el concepto de la "libertad de trabajo" que representó, en materia laboral, el contenido clásico de las constituciones liberales. Dicho principio fue consignado en nuestras Constituciones anteriores y la de 1979 lo establece en el inciso 13 del artículo 2 (dedicado a los derechos fundamentales de la persona) en los siguientes términos: "Artículo 2.Toda persona tiene derecho: 13.- A elegir y ejercer libremente su trabajo con sujeción a la ley": asi como en el cuarto párrafo del articulo 42 que afirma: "A nadie puede obligarse a prestar trabajo personal sin su libre consentimiento y sin la debida retribución".

Respecto a la significación y alcance de tales principios comenta Rafael Caldera que "A esta declaración no se asignan consecuencias juridicas. Sin embargo, tiene al menos una muy palpable, la de colocar fuera de la ley la vagancia, es decir "El estado habitual e injustificado de falta de profesión u oficio lícito". El deber del trabajo es, pues, un deber civico y moral, pero no 
sin efectos jurid:cos" (15). Refiriendose al trabajo como derecho, el mismo autor anota que "... no se trata aqui ya de del de. recho a trabajar en la actividad que se escoja, sino del título jurídico que a todo hombre se ré reconoce de hallar una ocupación para asegurar la subsistencia propia y la de su familia" (16).

Sin discrepancia con la opinión anterior, De la Cueva sostiene que "La sociedad tiene derecho a esperar de sus miembros un trabajo útil $\mathrm{y}$ honesto, $\mathrm{y}$ por esto el trabajo es un deber, pero el reverso de este deber del hombre, es la obligación que tiene la socidad de crear condiciones sociales de vida que permitan a 'os hombres el desarrollo de sus actividades" (17).

En armonia con estas interpretaciones doctrinales, encontramos algunas normas de nuestra Constitución que abonan similac concepción respecto a aquellos principios. En relación al derecho al trabajo podemos mencionar el inciso $15 \mathrm{del}$ articulo 2, que señala como derecho fundamental de la persona "...alcanzar un nivel de vida que le permita asegurar su bienestar y el de su familia". El ya c:tado articulo 42 en la tercera frase de su primer párrafo señala que "Corresponde al Estado promover las condiciones económicas y sociales que eliminen la pobreza y aseguren por igual a los habitantes de la República la oportunidad de una ocupación útil y cue los protejan contra el desempleo y el subempleo en cualquiera de sus manifestaciones". El también ya citado artículo 80 im pone al Estado el deber de "promover el bienestar general", y el artículo 110, sobre principios generales del régimen económico, indica en su segundo párrafo que "El Estado promueve el desarrollo ecorómico y social mediante el incremento de la producción y de la productividad, la racional utilización de los recursos, el pleno empleo y la distribución equitativa del ingreso".

De las op:niones autorizadas que hemos citado, y otras más que por economía omitimos consignar (18), así como de las nor-

(15) CALDERA, Rafael... Derecho del Trabajo, El Ateneo, Buenos Aires, 1960, pp. $178-179$.

(16) Loc. cit.

(17) DE LA CUEVA, Mario... El Nuevo Derecho Mexicano del Trabajo, Editorial Porrúa S.A., México, 1978, Tomo I, p. 109.

(18) P. ej. CABANELLAS, Guillermo, en Compendio de Derecho Laboral y TISSEMBAUM, Mariano, en Tratado de Derecho del trabajo. 
mas transcritas, se puede concluir que el ejercicio del derecho al trabajo y el cumplimiento, correlativo, del deber de trabajar, solamente son posibles en el marco de un orden social y económico que ofrezca a las personas la oportunidad efectiva de desempeñar una ocupación útil para sí mismas y para la sociedad. En nuestra realidad actual esto parece aún algo remoto, según lo anotan Rubio y Bernales: "Si partimos del hecho comprobado que en el Perú un $15 \%$ de la población económicamente activa carece de trabajo y un $35 \%$ más está subempleada, podemos concluir rápidamente que mal puede decirse que el trabajo es un deber a cumplir y menos aún que es un derecho satisfecho" (19). Los mismos autores, enjuiciando el régimen económico previsto en la Constitución sostienen que "...con un modelo económico global como el elegido, poco queda hacer al Estado para optimizar el nivel de empleo en el país, es el propio modelo el que ha limitado $y$, previsiblemente, seguirá limitando el desarrollo social en este aspecto" (20). De lo cual concluyen que "...la solución al problema del empleo estará en un profundo cambio de estructuras, que altere por completo la lógica del lucro predominante en el sistema capitalista" (21).

En esta perspectiva, el derecho al trabajo y el deber de trabajar, como principio de la vida social, aparecen claramente como cimientos de un nuevo orden social y un nuevo Estado, más que como derecho y deber que puedan realizarse dentro de la socidad liberal capitalista.

4) Los principios antes enunciados y comentados forman parte de una nueva concepción de la sociedad y el Estado que dificilmente podrá realizarse bajo la vigencia de nuestra actual Const tución, pues si bien ésta ha sido generosa y avanzada, desde el punto de vista social, en la formulación de principios y aún de normas programáticas, no es menos cierto que su concepción económica implica una profunda contradicción con aquellos principios, al or:entarse decididamente hacia una economia de fundamento capitalista. Los postulados del constitucionalismo social in-

(19) RUBIO, Marcial y BERNALES Enrique... Op. cit., pp. 578-579.

(20) Ibidem., p. 580 .

(21) Ibidem., p. 581 
sertos en la Constitución de 1979, justos y valederos en si mismos, se verán obligados a una difícil e incómoda convivencia con principios económicos y concepciones sobre el mercado y la propiedad tipicas del liberalismo económico. Así, nuestra Constitución encierra, desde su gestación, una profunda e insalvable ambigüedad conceptual y política, que hace presagiar para ella una vida azarosa e incierta. Ello no significa que hubiera sido preferible excluir de su texto los principios del constitucionalismo social, porque aún dentro de su compleja ubicación ellos contribuirán a sostener e impulsar el necesario proceso de cambio de estructuras que requiere el país y a consolidar, aún dentro del marco de una economia capitalista, ciertos derechos importantes para ios trabajadores.

Debe tenerse presente, en relación a este tema, que aquí se ha tratado del trabajo en sentido general, como "hecho social" mediante el cual "...se hace posible no tanto la vida del individuo que lo presta, como la vida social misma" (22). No se le ha visto como el objeto especifico del Derecho del Trabajo, esto es, como trabajo subordinado y por cuenta ajena. Por ello. refiriéndose a sus propios comentarios sobre el deber de trabajar, Caldera formula una interesante apreciación que creemos perfectamente válida para toda la temática del trabajo como principio de la organización social. Dice el autor mencionado: “... por trabajo, en este caso no se puede entender solamente el trabajo subordinado, ni menos el trabajo industrial, ni solamente el trabajo manual, sino el trabajo en todas sus formas: desde el de un profesor en su cátedra hasta el de un obrero en el fondo de una mina, pasando por el de una madre en su hogar" (23). Concepto éste más amplio que el del trabajo regulado por el Derecho del Trabajo al cual se referirán los capitulos siguientes, aunque intimamente vinculado a aquél en cuanto le sirve de fundamento e inspiración.

(22) CALDERA, Rafael, op. cit., p. 79.

(23) Ibidem., p. 178. 


\section{LA CONSTITUCION COMO FUENTE DEL DERECHO DEL TRABAJO}

A. Planteamiento doctrinal

La Constitución destina el Capitulo $\mathrm{V}$ de su Título $\mathrm{I}$ al trabajo. Como sabemos, el Título I se denomina "Derechos y Deberes Fundamentales de la Persona" y en sus siete capitulos desarrolla el enunciado de aquellos derechos bajo los rubros de derechos de la persona, de la familia, de la seguridad social, salud y bienestar, de la educación, la ciencia y la cultura, del trabajo, de la función pública y derechos politicos. La ubicación que se ha dado al capítulo sobre el trabajo indica la significación que la Constitución otorga a los derechos derivados o vinculados a él como derechos fundamentales de la persona.

Como ya lo señalamos anteriormente, nuestra actual Constitución es innovadora en el hecho de agrupar las normas constitucionales sobre el trabajo en un capítulo especial, lo que no sucedió con las Constituciones de 1920 y de 1933 que incluyeron sus escasas normas laborales en sus títulos sobre Garantias So. ciales, la primera, y sobre Garantias Nacionales y Sociales, la segunda.

Las normas incluidas en el Capitulo V, a diferencia de aquellos principios que hemos analizado en el punto anterior, constituyen, salvo algunas pocas excepciones, normas referidas al trabajo subordinado, esto es, a aquél que generalmente se considera como objeto propio del Derecho del Trabajo. En este sentido, aquellas normas constituyen fuentes formales del Derecho del Trabajo. Como lo señala Tissembaúm, tales normas "Constituyen disposiciones fundamentales y rectoras del ordenamiento jurídico y politico, debiendo ajustarse a las mismas las otras fuentes formales" (24).

TISSEMBAUMM, Mariano, op. cit., p. 476. 
Pero, no existe plena uniformidad en la doctrina del Derecho Laboral respecto al valor y significación de la Constitución como fuente formal. Para Cabanellas, "lo más común es qua esos principios y preceptos carezcan de vigencia inmediata, por requeri. para aplicarse en la práctica y por los tribunales, una ley especial, que no siempre se dicta después o que restringe en exceso el propósito de los constituyentes" (25). Caldera sostiene opirión parecida, aunque admite que, por excepción, puedan darse normas constiutcionales de aplicación inmediata. Prefiere, sin $\bullet \mathrm{m}$ iargo, ub carlas como "principios inspiradores" de la legislación laboral, sntes que como mandatos directos (26).

De la Cueva, comentando en este punto la Constitución mexicana sostiene, en cambio que "...es también una fuente formal del derecho, porque si bien contiene principios generales, se encuentran asimismo en ella normas concretas de aplicación automát:ca, como el principio de la jornada máxima o la protección al salario" (27). Por su parte, Alonso Garcia distingue entre dos significaciones de la Constitución como fuente: fuente mediata, en cuanto sirve de punto de partida para que los textos legales de aplicación directa no sufran desviación de la fuente constiturional, y "...fuente inmediata, singularmente en aquellos supuestos en los que por defecto de texto legal que hubiese debido desa. ircllar el correspondiente precepto constitucional, las normas contenidas en las propias Léeyes Fundamentales actúan como textc de aplicación directa..."(28). Agrega, además, que pueden servir como principios orientadores, e, incluso, estimulantes de 1 obra del legislador.

Coincidiendo básicamente con las opiniones de De la Cueva y Alonso García, Tissembaúm sostiene que "El imperio de las normas constitucionales deriva, en cuanto a su inmediatez, de la característica con que se redacta la disposición consiguiente" (29).

(25) CABANELLAS, Guillermo, Compendio de Derecho i,aboral, Bibliográ. fica Omeba, Buenos Aires, 1968, p. 183.

(26) CALDERA, Rafael, op. cit., p. 205

(27) DE LA CUEVA, Mario, op. cit., p. 129.

(28) ALONSO GARCIA, Manuel, op. cit., 167.

(29) TISSEMBAUM, Mariano, op. cit., p. 477. 
Asi, distingue entre "disposiciones constitucionales de tipo programático que sólo enuncian aspiraciones, propósitos y or'entaciones de carácter general" de otras "que determinan en modo imperativo el precepto, por la redacción consiguiente del texto, y son de aplicación automática, sin necesidad de leyes posteriores, pero que pueden dictarse para reglamentar su ejercicio..." (30). Este autor cita en su apoyo a los tratadistas españoles Bayón Chacón y Pérez Botija que hacen una distinción entre normas de ejecución inmediata posible y normas de valor programático, entre las cuales separan aquéllas que enuncian un futuro legislativo o un sistema económico-social que debe ponerse en marcha y aquéllas que sólo tienen un valor declarativo o teórico, sirviendo únicamente como princip:os orientadores. Mencionan tales autores como ejemplo de estas últimas la expresión "el trabajo es un de. recho $y$ un deber" (31).

B. Significación y jerarquia de la Constitución de 1979 como fuente del Derecho del Trabajo

Entre las normas constitucionales hay algunas de claro sentido programático como las conten'das en los articulos 42,43 -salvo lo referente a remuneraciones minimas vitales-_ $45,46,47$, $50,52,53$ y 56 . Otras, podemos considerarlas como de aplicación inmediata o directa, lo que no implica, como lo señala Tissembaúm, que no puedan dictarse leyes que regulen su ejercicion prec'sen otros detalles necesarios para su aplicación. No obstante, por importar el reconocimiento de derechos subjetivos no podria sostenerse que la falta de regulación legal impide o posterga su ejercicio hasta que ésta se dicte. Es el caso del articulo $4 \frac{4}{1}$ (en lo referente a la jornada de trabajo y a algunos otros be. neficios individuales alli previstos, pues respecto a otros e! ar. tículo tiene un carácter programát co); del artículo 48 (estabilidad laboral); del artículo 49 (pago preferencial de beneficios sociales y plazo de prescripción); del artículo 51 (derecho de sindicalización); del artículo 54 (convenciones colectivas); del artículo 55 (huelga); y, del articulo 57 (principios de interpre. tación).

(30) Loc. cit.

(31) Ibidem., p. 478. 
Poi lo demás, todas estas instituciones del Derecho Laboral se encuentran, en el Perú, normadas por disposiciones legales. tanto por leyes en sentido estricto cuanto por normas de carácter :eglamentario, con la excepción del articulo 57 que, por su na. turaleza, no requiere mayores desarrollos y ha tenido manifesta. ciones en la jurisprudencia laboral. De modo que la verdadera función que tendrán las normas constitucionales, tanto las de ca. rácter programático como las de ejecución inmediata, será la die servir de criterio para juzgar y establecer las modificaciones, adecuaciones o eventuales ampliaciones que requiera la legislación vigente.

El hecho de que la Constitución no sea mayormente innovadora en materia laboral no resta a sus normas valor o significación, pues como lo señaló la ponencia de la Comisión Especial de la Asamblea Constituyente No 12, sobre Trabajo, “...la inestabilidad política del país, la provisionalidad de los gobiernos democráticos, el desconocimiento cuando no la violación de las conquistas sociales, son razones suficientes para proponer la elevación de los derechos relativos al trabajo al rango de normas constitucionales. Sólo de esta manera se logrará que esos princ:pios adquieran validez y persistencia" (32).

Se ha pretendido, por consiguiente, dar a los derechos laborales la garantia que consiste en constitucionalizarlos, beneficiándolos con el carácter de superlegalidad que posee la Constitución. De tal manera, la legislación tendrá que respetarlos, no pudiendo restringirlos o negarlos. Además, ello les permitirá gozar del an: paro de las garantias const tucionales establecidas en el texto constitucional para la protección de los derechos fundamentales.

Ahora bien, en la estructura del orden jurídico la Constitución representa la norma de mayor jerarquia e importancid, a la cual cieben supeditarse, formal y materialmente, las demás normas que integran dicho ordenamiento. "El principio supraordinario que emana de la Constitución - afirma Rubio- es el principio de constitucionalidad de todo el sistema juridico y, por su-

En Actualidad Lahoral, Lima, Marzo 1979, p. 34. 
puesto, del sistema legislativo. Simplificadamente, este principio señala que las normas constitucionales tienen primacia por sobre cualquier otar norma del sistema y que, en caso de que cualquiera otra norma se oponga de alguna manera a la norma constitucio. nal, se aplicará la norma constitucional sobre ella" (33).

¿Cómo debe entenderse la aplicación de este principio en $\mathbf{r}$. lación a la jerarquía de las fuentes del Derecho Laboral?. De la Cueva, después de señalar que el principio de constitucionalidad implica que las leyes no pueden contrariar, restringir ni ampliər el contenido de las normas constitucionales sostiene que "El de. recho del trabajo acepta los dos primeros términos - contrariar o restringir - de los axiomas, por lo que sus normas no pueden contravenir ni restringir los beneficios que el pueblo otorgó a los trabajadores en la Declaración de derechos sociales, pero como son beneficios minimos... las fuentes formales subconstitucionales no sólo pueden, sino tienen como misión ampliar los beneficios..." (34).

En el mismo sentido opina Alonso Garcia: "El prin:ip:o de norma más favorable, y el respeto a las condiciones más beneficiosas establecidas con anterioridad, no suponen desconocimientc de la jerarquia normativa o vulneración de ésta. Su admisién po: normas de rango jerárquico adecuado, y su mismo sentido, de. muestran cuanto sostenemos. Pucs como tales normas más fave. rables no contienen nunca una disposición que siendo de rango inferior a otra, haya de resultar aplicable en contra de ésta, sino mejorándola y completándola" (35).

De esta manera, debemos concebir a los derechos laborales consignados en la Constitución como garantías mínimas, que en modo alguno pueden impedir su mejoramiento por la legislaciór - la creación, en el futuro, de otros derechos y beneficios no previstos en la norma fundamental. En este sentido, los derechos

(33) RUBIO, Marcial, La Legislación como fuente de Derecho en el Perú, en Derecho, Lima, Programa de Derecho de la Pontificia Universidad Católica, núm. 34, p. 14.

(34) DE I A CUEVA, Mario, op. cit., p. 132.

(35) ALONSO GARCIA, Manuel, op. cit., p. 292. 
que hoy aparecen en la Constitudión sólo reflejan o sepresentan u:n momento en el desarrollo social y económico del país y no pueden interpretarse como restrictivos respecto a aquallos nuevos derechos que surjan como consecuencia de un mayor desarrollo social y económico.

Finalmente, en relación a las fuentes constitucionaies, cabe mencionar un significado más que se les puede otorgar. Este es el de afirmar la autonomia del Derecho del Trabajo. Particular cníasis pone en este aspecto De la Cueva quien sostiene, en directa referencia a su propio texto constitucional, "...y como una consecuencia directa de la Declaración (el autor se refiere al art. 123 de la Constitución Mexicana), la autonomia plena del Derecho del Trabajo, lo que implica que sus raices y su sentido y su final dad se hallan en el artículo 123, por lo que es de este pre. cepto y no del derecho público ni del privado, de donde debe extraerse la orientación para la creación e interpretación de las normas concretas" (36).

No es radicalmente diferente la opinión de Cabanellas quien al referirse a la autonomia del Derecho Laboral considera que "En el terreno de los hechos, donde la autonomia laboral se ha: afirmado más v'gorosamente es en la legislación positiva, en una escala que va desde órdenes y reglamentos hasta preceptos o tị. tulos de las Constituciones, pasando por rillares de decretos y leyes" (37). Este autor, sin embargo reconoce y sostiene la vinculación de origen que une al Derecho Laboral con el Derecho Civil y admite a éste como fuente supletoria.

En eî Perú, como sabemos, dentro del marco de una legislación dispersa en normas de diversa jerarquia y en legislación de distintas materias, la definición del contrato de trabajo se en. cuentra en los articulos 1571 y 1572 del Código Civil y ha sido nuevamente incluida en el proyecto de Código Civil elaborado por la Com sión Reformadora en los artículos 1807, inciso b), 1825 y 1826, bajo la denominación de "Contrato de trabajo dependiente".

(36) DE LA CUEVA, Mario, op. cit., p. 79.

(37) CABANELLAS, Guillermo, op. cit., p. 162. 
Sin postular una separación absoluta e inconveniente, por 1 , demás, del Derecho Laboral y el Derecho Civil, creemos que el disponer de fuentes constitucionales propias, entre las cuales $f$ :guran declaraciones básicas, principios de interpretación y derechos fundamentales, robustece la autonomia del Derecho del Trabajo como disciplina jurídica y representa un importante estimulo para que en el Perú se pueda avanzar hacia la progresiva uni.ficación de la legislación laboral, como según parece fue el intento de la Comisión de Trabajo de la Asamblea Constituyente. para no mencionar sino el más reciente de los numerosos proyectos existentes en esa dirección.

\section{LOS PRINCIPIOS DE INTERPRETACION DEL DERECHO DEL TRABAJO EN LA CONSTITUCION DE 1979}

El Derecho del Trabajo posee principios propios de interpre. tación, que responden a su naturaleza peculiar y a su finalidad. Señala Cabanellas al respecto que "La interpretación laboral parte del sistema interpretativo general, que suelen concretar los códigos civiles, para establecer luego sus reglas especiales, fundadas en los caracteres propios del Derecho del Trabajo y en la condición peculiar que dentro de èl se crea para el trabajador" (38). De la afirmación anterior se desprende que el Derecho Laboral no se aparta o deja de lado los clásicos métodos de interpretación del derccho, a saber, los llamados literal o gramatical, lógico, histórico y sistemático, que tienen plena validez dentro de su ámbito, pero la función de tales métodos es complementada con principios o reglas propias de interpretación que unidas a los ci. tados métodos deben contribuir a la mejor comprensión de las normas del Derecho del Trabajo.

Considera Alonso Garcia que tales principios constituye: "...verdaderas normas que inspiran - por la necesaria obediencia al mandato en ellas contenido- el sentido de las disposicio. nes reguladoras del trabajo, definen el significado y alcance de las relaciones cuyo objeto es la prestación libre de un trabajo

IBIDEM., p. 233. 
por cuenta ajena, $y$, en suma, sirven al juez y al intérprete para determinar la genuina y verdadera expresión de los acuerdos entre partes o de la rormativa aplicable, cuando surge el litigio o se suscitan las diferencias entre los sujetos interesados" (39).

La doctrina difiere, aunque no sustancialmente, en la enunciación de aquellos principios interpretativos, pero existe coincidencia acerca de un núcleo básico de ellos, que nuestra Constitución ha recogido en diversos artículos del Capitulo $V$ de su Título Primero, según veremos a continuación.

\section{A. Irrenunciabilidad de derechos}

Este principio se encuentra claramente enunciado en el ar tículo 57, que señala en su pr'mer párrafo: "Los derechos reconocidos a los trabajadores son irrenunciables. Su ejercicio está garantizado pcr la Constitución. Todo pacto en contrario es nulo".

Este principio es consecuencia del carácter de orden público que tienen las normas laborales $\mathrm{y}$, asimismo, del carácter tuitivo o protector de este derecho, que determina que las normas que otorgan o reconocen derechos y beneficios al trabajador no puedan ser objato de renuncia o negociación por éste. Este limite impuesto a la voluntad del trabajador se justifica plenamente por la función protectora que cumple el Derecho del Trabajo respecto de la parte débil de la rzlación laboral, a la que se pretende tutelar frente a la ośra parte que, por su posic'ón más fuerte, podria forzar al trabajador a aceptar condiciones de trabajo y remuneraciones que implicaran una renuncia a sus derechos y beneficios fundamentalcs. Por ello, el Derecho Laboral está básicamente conformado por normas de orden público frente a las cuales no puede prevalecer la voluntad de las partes, aunque una de ellas sea la del propio trabajador.

Este principio reconoce sin embargo algunas excepciones o matices, que disminuyen su rigidez cuando ella pueda resultar perjudicial al trabajo, por lo que existen algunas leyes que permi-

ALONSO GARCIA, Manuel, op. cit., p. 301. 
ten la compensación de derechos, por la que el trabajador puede sustituir, a su elección, un derecho concedido genéricamente por la ley por otro beneficio, generalmente económico (40).

Expresión de este mismo princip:o, aunque no referida exclusivamente a derechos de carácter laboral, es la contenida en el segundo párrafo del artículo 42, según el cual "En toda relación laboral queda prohibida cualquier condición que impida el ejercicio de los derechos constitucionales de los trabajadores o que desconozca o rebaje su dignidad".

La sanción al incumplimiento de estas normas es la nulidad del pacto que implique renuncia de derechos, como lo establece el articulo 57.

\section{B. Principio "pro operario"}

Este es un principio muy importante y aceptado generalmente por la doctrina laboral, que ha sido consignado en al segundo párrafo del artículo 57 en los términos siguientes: "En la inter. pretación o duda sobre el alcance y contenido de cualquier disposición en materia de trabajo, se está a lo que es más favcrable al trabajador".

Señala Tissembaúm el contenido exato de este principio cuando afirma: "Dos aspectos encara el mismo en su realización: a) el de la aplicación de la norma más favorable al trabajador, cuando existen varias de fuentes distintas; b) el que interpreta situaciones dudosas de la norma o de los hechos en favor del trabajador" (41).

En armonía con la opinión citada, coincidente con las de otros autores, se puede comprender dentro del principio "pro ope. rario" las siguientes aplicaciones concretas o principios específi-

(40) Es, por ejemplo, lo que ocurre con las vacaciones, pues la ley permite la compensación de hasta 20 dias en el caso de obreros (Ley 13683. Art. $3^{\circ}$ ) y 15 dias en el caso de empleados (Ley 9049, Art. 2\%), a cambio de una remuneración extraordinaria.

(41) TISSEMBAUM, Mariano, op. cit., p. 539. 
cos: 1. In dubio pro operario, 2. La norma más favorable, y, 3. La condic'ón más beneficiosa.

1. El principio "indubio pro operario".-- En sentido especifico, implica que en presencia cie una duda acerca del contenido o alcance de una norma el intérprete deberá escoger la interpretación que sea más favorable al trabajador. Señala al respecto Alonso García que "El principio pro-operario no es, pues, principio judicial, sino en cuanto -..y sólo en cuanto- de la interpretación de la norma, llevada a cabo por el juez, quepa deducir varios sentidos posibles - todos lógicos y justos-, de los que alguno sea más favorable al trabajador que el otro o los otros" (42). Para Cabanellas, a su vez, "...para resultar aplicable hay que cncontrarse ante una duda normativa, y una duda que no haya podido resolverse poz reglas explicitas legales o convencionales" (43).

Mientras que para Cabanellas este principio es aplicable t:o sólo a la ley, como norma de fuente estatal, sino también a los convenios colectivos, los usos y costumbres $y$, en general, a todas las disposiciones laborales (44) otros autores como Tissem baúm (45) y Barassi (46) estima muy d'scutible su aplicacióti respecto a los convenios colectivos, arguyendo que en ellos la posición débil de la parte laboral, que sirve de fundamento al principio "pro-operario", ha desaparecido o disminuido significativa. menie, al haberse equilibrado la relación empleador-trabajador por la acción colectiva o sindical del segundo elemento.

Para Tissembaúm, además, este principio es igualmente apli. cable a la valoración de hechos o situaciones dudosas y se traduce, en este aspecto, en el principio procesal laboral de la inver-

(42) ALONSO GARCIA, Manuel, op. cit., p. 302.

(43) CABANELLAS, Guillemo, op. cit., p. 237.

(44) Loc. cit.

(45) TISSEMBAUM, Mariano, op. cit., p. 542.

(46) BARASSI, Iudovico... Tratado de Derecho del Trabajo, Buenos Aires, Editorial Aifa, 1953. Tomo I, p. 243. 
sión de la carga de la prueba (47), principio recogido por nuestro procedimiento laboral (48).

2. La norma más favorable.- Esta aplicación del principio "pro-operario" tiene como supuesto la coexistencia de una pluralidad de normas laborales, de distinta fuente, aplicables a una situación concreta. En esta hipótesis, el indicado princip:o "...se refiere a la vigencia de la que establece condiciones más venta. josas, para lo cual se requiere el análisis comparativo e interpretat:vo de sus disposiciones, para definir su vigencia de acuerdo al citado principio" (49).

Con relación a este principio se plantea el problema de ?a jerarquia de las normas juridicas, que en materia laboral sufre algunas alteraciones como consecuencia de la aplicación del aludido principio. Pero, en realidad no existe violación de la estructura jerárquica del orden juridico, pues teniendo las disposiciones legales el carácter de derechos minimos en materia laboral, la aplicación de una norma de inferior jerarquía que contenga un beneficio o norma más favorable no implica violación de la norma jerárquicamente superior, como ya se ha demostrado en otra parte de este trabajo en relación al valor de la Constitución como fuente formal del Derecho del Trabajo (50).

Otra cuestión sobre la que se discute con referencia a este postulado es la forma concreta de aplicarlo, en cuanto ella abre dos posibilidades: la de aplicar la norma más favorable en su integridad o totalidad o la de aplicar simultáneamente las diversas normas, tomando de cada una de ellas lo más favorable al trabajador. La doctrina conoce la primera opción como la teoria de la inescindibilidad y a la segunda como la teoria de la acumulación Tambićn en este campo puede surgir conflicto entre lo que se considere la norma más favorable para un trabajador y la que sea más favorable para un grupo o categoria de trabajadores. En tal supuesto, Cabanellas no duda en afirmar que la interpreta-

(47) TISSEMBAUM, Mariano, op. cit., p. 543.

(48) Ver. Decreto Supremo, No 006-72-TR, Art. 34, y Decreto Supzemo No 03-80-TR, Art. 32.

(49) TISSEMBAUM, Mariano, op. cit., p. 539.

(50) Ver. pág. 16. 
ción debe inclinarse del lado en que se encuentre el interés general, y no el particular, de los trabajadores (51).

3. La condición más beneficiosa.- Alonso García relieva el significado de este principio que, siendo una aplicación concreta del principio "pro operario", posee peculiaridad pues "supone la existencia de una situación concreta anteriormente reconocida y la cual queda respetada precisamente en función del juego que presta la aplicación de la norma más favorable, sentido preferencial que opera, en general, en las relaciones contrapuestas" (52). Como señala el mismo autor, el respeto de tales condiciones más beneficiosas puede efectuarse por ley o norma legal, costumbre o convenio colectivo. Se trata, en buena cuenta, de que una norma posterior aplicable a situaciones generales, no resulte perjudicial o menos benef:ciosa para el trabajador que la situación especifica de que gozaba.

Algunas expresiones de este principio existen en nuestra legislación. Por ejemplo, el articulo 8 del Decreto Supremo 009 del 26 de Mayo de 1962, reglamentario de las Leyes 13790 y 13842, sobre compensación de tiempo de servicios de obreros, señala que dicha reglamentación no comprende a "los trabajadores sujetos a regimenes especiales que contemplen beneficios superiores a los que establecen las leyes 13790 y 13842 , en cuyo caso continuarán disfrutando los beneficios mayores". Similar situación se contempla en el artículo 5 del Decreto Ley 21106, relativo al salari's obrerc en dia feriado.

Pese a la redacción poco precisa del segundo párrafo de! artículo 57 pensamos que él contiene en su enunciado las tres aplicaciones del principio pro operario a que acabamos de referi:nos, toda vez que no son en absoluto contradictorias sino más bien complementarias entre si, por provenir de una matriz común. Por lo demás, si bien este principio adquiere por vez primera rango constitucional $e$, inclusive, rango normativo, se encuentra. en sus diversas aplicaciones, contenido en nuestra legislación y jurisprudencia laboral.

(51) CABANELLAS, Guillermo, op. cit., p. 237.

(52) ALONSO GARCIA, Manuel, op. cit., p. 304. 


\section{Igualdad de trato}

Este otro principio interpretativo del Derecho Laboral en cuentra expresión en dos artículos del texto constitucional. Ei artículo 42 establece que "E1 trabajo en sus diversas modalidades, es objeto de protección por el Estado, sin discriminación alguna y dentro de un régimen de igualdad de trato". El articulo 43, en su segundo párrafo señala: "El trabajador, varón o mujer, tiene derecho a igual remuneración por igual trabajo, prestado en idénticas condiciones al mismo empleador".

Este principio tampoco es nuevo en nuestra legislación. pues ya está consagrado en el artículo 1572 del Código Civil que al definir el conten:do mínimo del contrato de trabajo menciona " ${ }_{\lambda}$ igualdad del salario, sin distinción de sexo, por trabajo igual...",

Con la vigencia de este principio se pretende "...evitar las arbitrariedades que pueden surgir de tratos desiguales que no tie. nen fundamento alguno..." (53). Principalmente, se busca pro.teger a las mujeres, los menores y los inmigrantes, para ponerios a salvo de un trato discriminatorio que seria contrario al propósito de justicia e igualdad que persigue el Derecho del Trabajo. Naturalmente, este principio no puede llevar a la concepción extrema de una igualación absoluta en las remuneraciones y condiciones de trabajo y, por ello, el precepto comentado exige, como fundamento para exigir dicha igualdad de trato, la igualdad del trabajo, la identidad de las condiciones y su prestación al misme empleador.

\section{La retroactividad benigna}

No se trata propiamente de un principio de interpretación de la ley laboral, sino de una cuestión relacionada a su vigencia en el tiempo, pero que por lá importancia que reviste para la aplicación del derecho laboral la consideramos en este capitulo.

El principio general, orientado a dar seguridad al orden juridico es, como sabemos, el de la irretroactividad de la ley. De

TISSEMBAUM, Mariano, op. cit., p. 549. 
acuerdo con su formulación clásica, la ley nueva rige para lo futuro, en tanto que los actos celebrados con anterioridad a su vigencia se rigen, en cuanto a su validez y a sus efectos, por la ley vigente al momento de su celebración o acontecimiento.

Este princip:o lo consagra nuestra Constitución en su articulo 187, segundo párrafo, el cual, sin embargo, permite la retioacti. vidad de la ley en materia penal, laboral o tributaria cuando es más favorable al reo, trabajador o contribuyente, respectivamente.

El sentido en que debe tomarse esta retroactividad, llamada benigna, en materia laboral es el que señala nitidamente De la Cirva cuando sostene: ". . las leyes de trabajo son de aplicáción inmediata y rigen la vida y los efectos de las relaciones de trabajo, de las ya formadas y de las futuras, a partir de su vigencia..." (54). Refiriéndose a la misma cuestión, Brassi anota: "Ia conclusión es que la regla de la irretroactividad está lejos de ser absoluta porque ella presupone una equidad en su aplicación que puede faltar cuando se trate de relaciones juridicas que determinan situaciones duraderas. Para éstas, la sujeción a la ley vieja o al convenio colectivo anterior o, aún peor, al reglamento interno precedente, representaria una iniquidad insoportable..." (55).

De esta manera, la ley laboral, o el convenio u otras fuentes, rige de inmcdiato, se aplica a todas las relaciones laborales, como ocurre con las normas de orden público, por la naturaleza de los intereses que tutelan. Esta es la clase de retroactividad que alguncs llaman atenuada o de grado minimo, para distinguirla de la retroactividad de segundo grado que implicaria aplicar la lev a situaciones o efectos ya producidos bajo la ley anterior, modi. ficándolos, lo que, en nuestra opinión, no parece ser la isténción de la Constitución ni es tampoco postulado que impulse el Dere. cho del Trabajo.

(54) DE LA CUEVA, Mario, op. cit., p. 150.

(55) BARASSI, Ludovico, op. cit., p. 257. 


\section{LOS DERECHOS LABORALES EN LA CONSTITUCION}

En el Capitulo V del Título I, se consagran y rzconocen un conjunto de derechos laborales, individuales y colectivos, que ocupan el grueso de dicho capitulo. Se ha sostenido, y con fundamento, que la enumeración de tales derechos laborales no ha significado ninguna innovación en el contenido de nuestro Derecho del Trabajo, pues todos ellos, de una forma u otra, ya se encontraban plasmados en la legislación laboral peruana (56). Si bien esta afirmación es cierta, ya hemos destacado, a propó. sito del estudio de las fuentes que la constitucionalización de ta. les derechos posee un signif:cado trascendente porque otorga jerarquia constitucional a las fuentes y principios del derecho laboral.

En parte debido a ese hecho y, en parte también por razcnes de espacio, no pretendemos en este análisis abordar todos y cada uno de los derechos laborales, sino tan sólo algunos de ellos que, en nuestro concepto, revisten gran importancia o resul. tan polémicos en relación a su contenido y al alcance que ha pretendido darles la Constitución. Por ello, comentaremos a con tinuación únicamerite las normas constitucionales referentes a es.

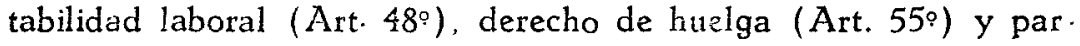
ticipación de los trabajadores en la empresa (Art. 56 $6^{\circ}$.

A. Estabilidad laboral

1. El concepto de estabilidad laboral.- Como es sabido, el derecho de los trabajadores a la estabilidad laboral fue consagrade por vez primera en la Constitución Mexicana de 1917. cuyo Artítulo $123^{\circ}$, inciso A, numeral XXII definió el concepto en los siguientes términos: "El patrono que despide a un obrero sin causa itstificada o por haber ingresado a una asociación o sindicato, o por haber tomado parte en una huelga lícita, estrrá obli-

(56) PASCO, Mario... El Tema del trabajo y la nueva Constitución en "La Nueva Constitución y su aplicación legal". Lima, Francisco Campodónico $F$. y Centro de Investigación y Capacitación (cic). Coeditores, 1980 , p. 75 . 
gado, a elección del trabajador, a cumplir el contrato o a indem. nizarlo con el importe de tres meses de salario".

Definiendo doctrinalmente la estabilidad laboral, ha dicho De la Cueva: "La estabilidad de los trabajadores en los empleos comprende dos modalidades: la permanencia, persistencia o duración indefinida de las relaciones de trabajo y la exigencia de una causa razonable para su disolución. La primera parte de estas modalidades es la esencia misma de la estabilidad de los trabajadores en los empleos y la segunda es su seguridad o garantia; si esta seguridad falta, la estabilidad sería una mera ilusión. Pcr ello es que la exigencia de una causa razonable para la disolución de las relaciones de trabajo es uno de los aspectos furdamentales del problema" (57).

La estabilidad es una de las notas típicas del contrato o relación de trabajo, en el sentido de continuidad, permanencia o durabilidad de dicha relación, aludiendo, de este modo, al carácter indefinido que posee, que coloca en situación de excepción a los contratos de duración determinada. Pero el verdadero alcance de la estabilidad aparece en relación a la terminarión de la relación laboral por decisión unilateral del empleador, que comunmente se define como despido. Con referencia a esta posibilidad es que, en la doctrina y la legislación, se han configurado dos clases o regimenes de estabilidad en el trabajo: la estabilidad re. lativa y la estabilidad absoluta.

Para De la Cueva "Se habla de estabilidad absoluta cuando se niega al patrono, de manera total, la facultad de disolver una relación de trabajo por un acto unilateral de su voluntad y unicamerite se permite la disolución por causa justificada... Y se habla de estabilidad relativa cuando se autoriza al patrono, en grados variables, a disolver la relación de trabajo por un acto unilateral de su voluntad mediante el pago de una indemnización" (58). Por su parte, Cabanellas define en términos análogos las dos clases de estabilidad: “...la estabilidad relativa o

(57) DE LA CUEVA, Mario... Derecho Mexicano del Trabajo..., Méxicc Editorial Porrúa, 1964 8va. Edición, Tomo I, p. 755.

(58) DE LA CUEVA, Mario, Nuevo Derecho... op. cit., p. 221. 
durabilidad, minima garantia para el trabajador, indemnizable cuando se le despida sin justa causa, y la estabilidad absoluta o perdurabilidad, que consolida el nexo del trabajador con la empresa por cuanto sólo puede ser dado de baja en la misma con justificada causa" (59).

En sintesis, podemos afirmar que en el régimen de estabilidad relutiva un trabajador puede ser despedido por causa justificada o $\sin$ que exista causa justificada, "resolución "ad nutum", que se da por el simple ejercicio del poder empresarial" (60); en cambio, en el régimen de estabilidad absoluta el despido sólo procede cuando existe causa justificada.

2. La estabilidad laboral en el Perú.- En el Perú hemos pasado por tres etapas, claramente distinguibles, en cuanto al régimen de la estabilidad laboral. A partir de la Ley 4916, que reguló el régimen laboral de los empleados se implantó un sistema. de estabilidad relativa, según el cual superado el periodo de prueba de noventa dias, el empleado podía ser despedido sin causa justificada mediante un pre-aviso de noventa dias (Art. $1^{\circ}$ ), que podia ser sustituido por el pago de una indemnización equivalerite a la remuneración de esos noventa dias. (Art. 28, Reg. -Ley 4916). Lógicamente, de existir alguna causa justificada, o falta grace de aquellas enumeradas en el Art. $2^{\circ}$ de la Ley 4916, el Art. 294 del Código de Comercio y los artículos 12, 22 y 27 del Reglamen. to de la Ley 4916, el trabajador podia ser desped:do de inmediato sin el beneficio del pre-aviso o de la indemnización sustitutoria por omisión del mismo.

En el caso de obreros, el Decreto Ley 14221 del 23 de Oc. tubre de 1962 estableció un pre-aviso de sólo 15 días, sujeto a reglas análogas a las vigentes para el despido de los empleados. Pero esta norma duró poco, pues fue derogada por la Ley 14857 del 5 de Febrero de 1964, con lo cual se privó a los obreros del beneficio del pre-aviso de despido.

(59) CABANELLAS, Guillermo, op. cit., p. 702.

(60) ALONSO GARCIA, Manuel, op. cit., p. 602. 
Este régimen reconoció, sin embargo, algunos casos de mayor protección al trabajador en cuanto a su estabilidad, aunque con carácter excepcional. Ello ocurrió con los dirigentes sitidicales (61), los trabajadores enfermos (62) y los empleados con 15 ó 20 años de servicios (63).

Esta primera etapa terminó al promulgarse el 10 de Novienbre de 1970 el Decreto Ley 18471, que instituyó un régimen de estabilidad absoluta. Según dicha norma la estabilidad se adquiria pasado el periodo de prueba de tres meses y en virtud de ella el trabajador sólo podía ser despedido por falta grave, según la enumeración de los hechos que configuraban dicha falta tipificados en el artículo 2, o por reducción de personal o liquidación de la empresa, según el artículo 5. El trabajador despedido sin justificación podía reclamar, a su elección, la reposición en el trar bajo o el pago de una indemnización equivalente a noventa dias. Este régimen comprendia tanto a empleados como a obreros.

La tercera etapa, en la que hoy nos encontramos, se inicia con el Decreto Ley 22126 que deroga la ley anterior y establece un régimen caracterizado por la combinación de los dos regimenes precedentes. Así tenemos, una vez terminado el periodo de prueba que continúa siendo de tres meses, un período de estabilidad relativa que dura hasta que el trabajador cumple tres años ininterrumpidos al servicio del mismo empleador. Durante este periodo, el trabajador, obrero o empleado, puede ser despe. dido sin causa justificada con un pre-aviso de noventa dias cursedo por carta notarial o, en caso de omitirse el pre-aviso, mediante el fago cie una indemnización equival znte a noventa dias de remuneración según lo establecen los artículos 2 inciso b) y 28 . Naturalmente, creemos que en este lapso puede ser despedido el trabajador sin pre-aviso o indemnización si incurriese en falta grave prevista en el Artículo $4^{\circ}$. Pasados los tres años, el traba-

(61) Ver Resoluciones Supremas de 18 de Febrero, No 23 y de 20 de Abril de 1957.

(62) Ver Decreto Supremo N' 2-DT de 28 de Enero de 1954 y Ley 13724, Artículo 32, inc. g).

(63) Ver D.S. de 05 de Junio de 1953, D.S. No 19 del 4 de Noviembre de 1958 y Ley 15542, Art. 1o 
jador adquiere estabilidad absoluta y únicamente puede ser despedido por cometer falta grave o de mediar alguna de las situa. ciones excepcionales previstas en el artículo $10^{\circ}$. Si se produce un despido injustificado, esto es, sin mediar una falta grave, el trabajador puede optar por reclamar su reposición o una indemnización equivalente a doce meses de remuneración, con un tope máximo para cada remuneración igual al tope vigente para la compensación por tiempo de servicios (64). El nuevo régimen respetó la situación de aquellos trabajadores que bajo la vigencia de la ley anterior habian adquirido la estabilidad laboral por haber superado el periodo de prueba, como lo establece su artículo 2. inciso a).

3. La estabilidad laboral en la Constitución.-- Estando vigente el Decreto Ley 22126, se dicta la Constitución de 1:-9\%, que consagra este derecho en el artículo 48: "E1 Estado reconoce el derecho de estabilidad en el trabajo. El trabajador sólo puede ser despedido por causa justa, señalada en la ley y díbidamente comprobada".

En torno a los alcances de este artículo, es decir a si estabiece un régimen de estabilidad relativa o uno de estabilidad absoluta se ha iniciado una interesante discusión a la cual deseamos aportar algunos planteamientos. Para algunos autores nacionales, el artículo 48 no define un régimen de estabilidad $y$, por consiguiente, la ley puede escoger cualquiera de los existentes. En tai virtud, sostienen la constitucionalidad del Decreto Ley 22126. particularmente la de sus artículos $2^{\circ}$ inc. b) y $28^{\circ}$. En este sen tido, afirma Mario Pasco que "Si quisiéramos sostener que el Decreto Ley 22126 resulta ilicito porque contempla un plazo de tres años que la Constitución no señala, tendriamos que llevar el argumento hasta sus últimas consecuencias y decir que tampoco señala un plazo de tres meses. Y si no señala un plazo de tres

(64) El Articulo 6, inc. b) del D. Ley 22126 hace referencia al tope señalado en el Decreto Ley 21396, que es de 30 mil soles y era el máximo al dictarse el D.L. 22126. Pero, en nuestra opinión personal, dicha referencia está hecha al concepto mismo de la compensación por tiempo de servicics $y$, por tanto, al reajustarse éste con posterioridad mediante el D. Ley 22658 a la suma de 60 mil soles, entendemos que éste es el tope vigente para dicha indemnización especial. 
meses llegariamos por reducción al absurdo de sostener que la estabilidad en el empleo es un derecho que se alcanza desde el primer día de trabajo, concepción que no creo que haya estado en la mente de ninguno de los constituyentes si el plazo de tres meses no está en la Constitución, el plazo de tres años resulta igualmente válido y creo, por lo tanto, que el Decreto Ley 22126 puede subsistir exactamente en los términos en que está concebido $\sin$ que viole el derecho constitucional contenido en el articulo 48 " (65).

En cambio, otros autores sostienen la tesis contraria y de ella deducen la inconstitucionalidad parcial del Decreto Ley 22126. Entre tales opiniones destaca la de Jorge Rendón para quien “... el artículo $48^{\circ}$ de la Constitución ha derogado el inciso b) del artículo $2^{\circ}$ y el artículo $28^{\circ}$ del Decreto Ley 22126 que le permitian al empleador despedir sin causa justificada a los trabajadores que una vez que pasaban el periodo de prueba de tres meses no habian cumplido aún tres años de servicios, dándoles un pre-aviso de 90 dias calendario" (66).

Por nuestra parte, creemos que debe analizarse cuidaciosamente la redacción del artículo $48^{\circ}$ y el contexto en que se ubica, para desprender su verdadero sentido y alcance. La primera frase del artículo establece que "El Estado reconoce el derecho de estabilidad en el trabajo". Esta afirmación es, en efecto, genérica y principista por lo que seria legítimo desprender de ella que la Constitución no establece s'stema especifico alguno de estabilidad, pudiendo ser válida tanto la relativa como la absoluta. Pero, a nuestro juicio, la segunda frase del articulo aclara el sentido preciso del principio consignado en la primera frase, cuando asevera "El trabajador sólo puede ser despedido por causa justa señalada en la ley y debidamente comprobada". En otras palabras, el trabajador no puede ser despedido s'n causa justa como lo permite el artículo $28^{\circ}$ del Decreto Ley 22126 durante los tres primeros años del vínculo laboral. Uceda sostiene, al respecto, que "El aviso de despedida es la posibilidad que tiene el empleador de cesar la re-

(65) PASCO, Mario, op. cit., pp. 84-85.

(66) RENDON, Jorge, Manual de Derecho Individual del Trabajo, Ediciones Tarpuy, Lima, 1981, p. 106. 
lación laboral para aquellos trabajadores que todavia no tienen los tres años de servicios mediante el simple recurso de pasarle una carta notarial ind cándole que ya no continuará el vínculo laboral. Yo me pregunto ies esta una causa justa? Si analizamos habria que conceder que es una causa justa, porque no se sancionaria al empleador por su utilización. No podria alegarse que hay despedida injustificada, porque es una causal señalada por la ley" (67).

Discrepatios con esta respetable opinión porque, precisamente, el articulo 28? del Decreto Ley 22126 se refiere a "La resc'sión del vinculo laboral sin causa justificada de los trabajadores a que se refiere el inciso b) del artículo $2^{\circ}$ del presente Decreto Ley...", es decir, aquellos que no han cumplido tres años de servicios ininterrumpidos para el mismo empleador. Esta norma es concordante con el articulo $3^{\circ}$ de la misma ley que refiriéndose a los trabajadores con más de tres años de servicios establece que "Los trabajadores a que se refiere el articulo anterior sólo podrán ser despedidos por las causales previstas en el presente dispositivo legal...". $Y$ con el artículo 40 que empieza su redacción señalando "Constituyen faltas graves que dan lugar a la despedida justificada e inmediata del trabajador, las siguientes: (...)".

Por tanto, la hipótesis prevista en el articulo $28^{\circ}$ de la vigente ley de estabilidad laboral es la dei despido sin causa justificada, dentro de los tres primeros años de la relación laboral, con la única exigencia de cursar un pre-aviso notarial de noventa dias o, en sustitución, abonar el importe de la remuncración de esos dias, por lo que no puede reputarse quz la formalidad del pre-av so constiłuya una causa justificada. Por lo dcrós, en cste punto, el articulo $28^{\circ}$ es congrurnie con lo que cominnente se entiende como estabilidad relativa, esto es, la facultad discrecional del empleador de despedir al trabajador, con o sin causa justificada, con el único requisito en el segundo caso de un pre-aviso o una indimnización, o de ambas según los sistemas legales. Tal es la misma situación considerada y prevista ya en el artículo 1 ? de la ley 4916 y 1 artículo 28? de su reglamento (R.S. de 22.06.1928).

(67) UCEDA MALRER, Luis, Liscurso ci Rerista del FORO. Lima, 1979, I. 2-3-4, pp. $161-162$. 
No nos cabe la menor duda, al respecto, de que la posibilidad de un despido sin causa justa está prohibida por el artículo $48^{\circ}$ de la Constitución y que, en consecuencia, ésta ha optado por un sistema de estabilidad absoluta, en razón de lo cual las normas del Decreto Ley 22126 que permiten el despido sin causa justificada (Art. 2\%, inciso b) y el Art. 28\%) han devenido inconstitucionales en razón de su contenido material.

Por otro lado, no cabe pensar que a la luz de los distintos sistemas que ha experimentado el Perú en esta importante cuestión el constituyente haya empleado la expresión "sólo puede ser despedido por causa justa, señalada en la ley..." en un sentido distinto dal generalmente empleado, y haya querido comprender en él conceptos como el pre-aviso u otros semejantes. Si hubiera querido dejar abierta la opción a varios sistemas de estabilidad hubiera bastado enunciar la frase inicial del artículo $48^{\circ}$, o la utilización de un concepto más genérico como el que consagra el artículo $88^{\circ}$. de. la Constitución venezolana, Estado donde no existe la estabilidad absoluta, que se l'mita a señalar "La ley adoptará medidas tendientes a garantizar la estabilidad en el trabajo...". En cambio, cabe destacar la similitud existente entre el contenido de nuestro artículo $48^{\circ}$ y el artículo $123^{\circ}, \mathrm{A}, \mathrm{XXII}$ de la Constitución Mexicanci.

En lo que se refiere a la compatibilidad entre el periodo de prueba y la estab lidad laboral creemos que si bien la Constitución no lo mencicna, podria admitirse su existencia toda vez que se trata cle una institución casi universalmente admitida, cuya finalidad es, principalmente, para el empresario respecto al trabajdor “... apreciar en la práctica su capacidad profesional, la adaptación a la tarea que se le asignará, asi como descubrir, en la convivencia inmediata y más o menos prolongada, sus cualidades personales de toda indole que se valoren en el trabajo" (68). Pero, este periodo también conlleva beneficio para el trabajador, pues este puede, como lo señala Alonso "... comprobar si efectivamente el trabajo que se le ofrece puede por él ser desempeñado, y advertir 
además, si las condiciones genéricas y concretas a un t'empo, en que ha de desarrollarse su tarea, han de satisfacerle" (69).

Doctrinaria y conceptualmente el periodo de prueba, ciertamente breve de acuerdo a su finalidad, no es de naturaleza incompatible con la estabilidad laboral, ni relativa ni, tampoco con la absoluta. Inclus:ve, podria pensarse que es más necesario en un régimen de estabilidad ya que como apunta Cabanellas "El periodo de prueba es necesario a causa de las complejas obligaciones que contraen las partes. Cuando la tendencia imperante consiste en lograr la estabilidad del trabajador en su empleo, su inamovilidad --en ccasiones absoluta-, resulta evidente la necesidad de que las partes que contratan conozcan mutuamente sus cond ciones personales y profesionales" (70).

La conveniencia de que exista un psriodo de prueba, como el de tres meses previsto por nuestra legislación, no autoriza, sin embargo, a justificar un periodo de espera de la estabilidad absoluta de tres años, el cual carece de la finalidad que caracteriž̃: el periodo de prueba y que hace a éste necesariamente breve. No obstante, si con un criter'o estricto se estimase su incompatibil.dad con el artículo $48^{\circ}$ de la Constitución, creenos que la interpretación que debe prevalecer es la referente a la vigencia de la estabilidad laboral absoluta, no súlo por ser la más favorable al trabajador, sino, fundamentalnente, porque cntre la estabilidad absoluta claramente contenida en el articulo $48 \%$ y el periodo de prueba no previsto expresamente en él, no podria optarse por el segundo en desmedro de la primera. Más aún, cuando la defensa del periodo de prueba sirve, en real:dad, para sostener la vigencia de un periodo superior a éste como el de tris años que exige la ley vigente para alcanzar la estabilidad absoluta, lo que si configura una evidente vulneración de la norma constitucional. A este respecto, también podriamos sosiencr que si fuera licito un plazo de tres años para adquirir la estabilidad absoluta, tambićn podria admitirse un plazo de veinte o trénta años, con lo cual la estabilidad laboral absoluta se convertiria en un espejismo, lo

(69) ALONSO GARCIA, op. cit., p. 458.

(70) CABANELLAS, Guillermo, op. cit., pp. $487-488$. 
que consideramos no puedc haber sido la "mens legis" de los constituyentes.

Cabe anotar, para culminar estas reflexiones, que en México la estabilidad laboral absoluta se obtiene desde el inicio de la relación laboral, sin que exista un periodo de prueba, aunque el trabajador despedido dentro del primer año de servicios no puede optar por la reposición en el empleo sino únicamente por la indemnización correspondiente a despido injustificado, si fuera el caso $(71)$.

B. El derecho de huelga

Por primera vez en el Perú, la Constitución consagra el derecto de huelga. El articulo $55^{\circ}$ lo hace en los siguientes términos: "La huelga es derecho de los trabajadores. Se ejerce en la forma que establece la ley".

No se puede escatimar el valor de este reconocimiento por el texto constitucional, que responde a una tendencia generalizada cn el proceso constitucionalizador del Derecho del Trabajo. Por cilo, Cabanellas sostiene que "La cesación laboral concertada y colectiva, pcir iniciativa de los trabajadores - la huelga- ha concretado la máxima evolución juridica que cabe concebir, al pasar de execrado cicl to a derecho, proclamado con énfasis, y hasta con orgullo, por los constituyentes que han santificado en lo legal lo perseguido artes como aberración" (72).

Refiriéndose al precepto contenido en el articulo 55, Santisteran y Delgado opinan que "El reconocimiento en abstracto del derec'o de huclga y de otras garantias laborales significa en general, un avance en térninos técnico-juridicos y politicos" (73).

La redacción del artículo $55^{\circ}$ se inspira en la redacción del preánbulo de la Constitución de Francia de 1946 referente a la

(71) Ley Ecteral de Trabajo de México, Art. 49.

(72) CABANLLLAS, cp. cit., Tomo II, pp. 325-326.

(7今) SANTISTEVAN, Jorge y DELGADO, Angel, La Hueiga en el Perû, Lima, CEDYS, 1980, p. 304. 
huelga y en el Articulo $40^{\circ}$ de la vigente Constitución de Italia, las cuales consagran el derecho de huelga pero envian su regulación al dominio de la ley. Como apunta Pasco "Más importante que la exposición del artículo constitucional va a ser, sin duda, la ley que lo reglamenta. Es a esa ley a la que só!o podemos hacerle comentario una vez que el Estado se anime a ponerle el cascabel al gato" (74). Hay quienes piensan que esa indefinición del articulo, que remite prácticamente su propio contenido a la ley, puede devenir en una interpretación, según la cual en tanto no exista la ley reguladora del derecho no puede éste ser ejercido. Sale al paso de esta posibilidad interpretativa Cabanellas cuando afirma "El problema se plantea en el sentido de que, si este derecho sólo se ejerce dentro de los limites de las leyes que lo r $r-$ glamentan, mientras esas leyes no hayan sido dictadas, habría que llegar a la conclusión de que tal derecho no existe. Sin embargo, no es asi; el derecho de huelga puede ejercerse aún cuando no hayan sido dictadas leyes que lo reglamenten (75). Dicha afirmación es completamente justa, pues lo contrario implicaria una violación constitucional por omisión, es decir por impedirse el ejercicio de un derecho constitucional, por ausencia de la ley que debe regularlo.

En el Perú, la huelga ha estado regulada poz diversas disposiciones legales, básicamente normas del poder ejecutivo, que más que regularla o encauzarla han tenido un carácter restrict vo del derecho. Santistevan y Delgado anotan esta realidad: "... debe tenerse en cuenta que no existe por ahora en el Perú, ninguna norma que regule este derecho, salvo las muchas vigentes que contienen prohibiciones en vez de canales de implementación de la garantía constitucional" (76). La norma más antigua, en esta materia, fue el Decreto Supremo del 24 de Enero de 1913, dictado por el gobierno del Presidente Billinghurst, de carácter fuertzmente controlista, el cual después de haber caido en desuso fue revivido durante la segunda fase del gobierno militar, quien ante la protesta que ello generó lo declaró en suspenso mediante el Decreto Supremo 001-76-TR, del 3 de Febrero de 1976, situación

(74) FASCO, op. cit., p. 91.

(75) CABANELL AS, Guillermo, op. cit., T. II, p. 327.

(76) SANTISTEVAN, Jorge y DELGADO, Angel, op. cit., p. 304. 
juridica en la que permanece hasta el dia de hoy. Otras normas de los años 1920 y 1962, son las que hoy enmarcan el ejercicio de la huelga, sin que exista una normatividad integral y coherente sobre esta institución. Diversas otras normas de carácter sectorial establecen restricciones o prohibiciones al ejercicio de la huelga en determinadas actividades o situaciones. Refiriéndose a esta normatividad, Rubio y Bernales consideran que "La legislación sobre huelga, por lo tanto, ha sido esencialmente represiva y tendiente a suprimir el derecho por vía de facto. Una recta aplicación de la normatividad constitucional obligará a declararlas incompatibles con ella" (77).

El envio que hace el artículo $55^{\circ}$ a la legislación para la regulación del ejercicio del derecho de huelga hacer temer a algunos, teniendo en cuenta la tradición restrictiva de la legislación peruana sobre la huelga, que por esa via se pueda consagrar una legislación con similares características: "Al remitirse la Constitución a una ley implementadora del artículo $55^{\circ}$, da margen a que, dependisndo de la correlación de fuerzas de cada coyuntura futura, se pongan en práctica regimenes restrictivos y lim tativos al derecho de huelga..." (78).

En el hecho, ese temor ha cobrado cuzpo al aprobarse por el Senado de la República el 27 de Octubre de 1981 un proyecto de ley reglamentando el derecho de huelga, que ha sido renitido a la Cámara de Diputados para su revisión. Dicho proyecto contiene diversas disposiciones restrictivas del derecho de huelga que han merecido, incluso, la critica del Comité de Libertad Sindical de la OIT, por considerarlas poco democráticas y contrarias al princip:o de libertad sindical (79). Cabe mencionar entre los aspectos más inconvenientes del citado proyecto, su concepción restringida de la finalidad de la huelga (Art. 4\%), el debilitamiento de la organización sindical en la declaración de la huelga (Art. 6\%) y en su convocatora por crganizaciones de grado superior (Art. 8\%), la terminación de la huelga por sometimiento a arbitraje obligatorio cuando lo decida el gobierno en casos de interés general, lo

(77) RUBiO, Marcial y BERNALES, Enrique, op. cit., p. 237.

(78) SANTISTEVAN, Jorge y DELGADO, Angel, op. cit., p. 304.

(79) Informe del Comité de Libertad Sindical de la OIT, en Análisis Laboral. 
meración de los servicios esenciales en los cuales se limita el derecho de huelga, especialmente cuando queda a discreción del Gobierno determinar cuáles otros son "indispensables para la vida social" (Art. 17\%, inc. G), lo que posibilttaria limitar algunas huelgas si se considera esencial el servicio afectado, en base a consideraciones subjetivas o coyunturales.

Cabe destacar que la Constitución en su Artículo 619 reconoce el derecho de huelga a los servidores públicos, lo que representa una innovación muy positiva en nuestro ordenamiento jurídico. El referido proyecto de ley sobre la huelga comprende, también, la regulación del derecho de huelga de los servidores públicos, derecho que, según la Const'tución, no corresponde a los funcionarios con poder decisión o cargos de confianza, ni a los miembros de las Fuerzas Armadas y Policiales.

Coincidimos con la necesidad de dictar en el Perú una legisque obviamente restringe su ejercicio (Art. 16\% inc, c), y la enulación que regule el derecho de huelga y que, a la par que elimine las normas restrictivas que aún subsisten, encuadre su ejercicio dentro de limites adecuados, compatibles con el interés general. En tal sentido consideramos que una cuestión fundamental consiste en no subordinar el ejercicio del derecho de huelga a una calificación previa por parte de la autoridad de trabajo, lo que podria traducirse en una política restrictiva, sino tan sólo exigir el cumplimiento de determinados requisitos formales, tales como ma. yoría en la votación y un pre-aviso a la autoridad, para que éste pueda ser licitamente ejercido, quedando a salvo la potestad de la autor:dad de declarar ilegal una acción de huelga que no satisfaga dichas formalidades.

Otra cuestión que queremos dejar señalada estriba en anotar que de conformidad con la redacción del artículo 231 inciso a) de la Constitución, el derecho de huelga no puede ser suspendido bajo el Estado de Emergencia, pues dicha norma no lo menciona entre las garantias o derechos que pueden suspenderse en aquel régimen de excepción. En tal sentido, una norma que quisiera repetir la prohibición de la huelga bajo el estado de emergencia, como lo hiciera el Decreto Supremo No 11-76-TR, sería abiertamente inconstitucional. 
C. La participación de los trabajadores en la empresa

Este derecho aparece consignado en el Artículo 56 de la Constitución. Tal como está formulado también representa un avance a nivel del texto constitucional, aunque responde a una realidad existente en el pais. Tuvo, además, un débil antecedente en el Artículo 45 de la Constitución de 1933 que estableció que "El Estado favorecerá un régimen de participación de los empleados y trabajadores en los benefic:os de las empresas...".

En aplicación del mencionado artículo se dió en el Perú, el año 1948, un régimen de participación en las utilidades normado por el Decreto Ley 10908, que por la oposición de los sectores empresariales nunca fue aplicado, siendo finalmente sustituido por el sistema de la Ley 11672, aún vigente, que estableció una asignación anual sustitutoria de la participación en las utilidades de las empresas consistente en otorgar a los trabajadores una asignación equivalente a un porcentaje de sus remuneraciones, en función de sus años de servicio.

Recién a partir del año 1970 se avanza en el Perú hacia un veradero sistema de participación de los trabajadores en la empresa, al dictarse la Ley General de Industrias, Decreto Ley 18350 y, posteriormente, la Ley de Comunidad Industrial, Decreto Ley 18384, que establecieron el derecho de los trabajadores de las empresas industriales a participar en las utilidades, la gestión y la propiedad de las empresas. Dicha participación revestía un carácter colectivo, en lo referente a la gestión y la propizdad, para lo cual se instituyó el organismo denominado Comunidad Industrial, integrado por todos los trabajadores, obreros, empleados y ejecutivos, de las empresas. Dicha participación se producia reconociéndose a los trabajadores derecho sobre un porcentaje de la renta neta de la empresa, antes de impuestos, el cual alcanzaba en el sector industrial al $25 \%$ de dicha renta. La participación en la propi $=d a d$ se daba adjud canclo a la Comunidad Industrial acciones rcpresentativas del capital social de la empresa, originadas, ya sea en la reinversión y capitalización obligatoria del $15 \%$ de la renta neta o en la aplicación de d'cho porcentaje a la ad.quisición directa, e igualmente obligatoria, de acciones de propiedad de los socios de la empresa, cuando la empresa decidiera no 
reinvertir o su programa de reinvers ón no fuese aprobado por el Ministerio de Industria. Dicho mecanismo tenia como objetivo final que la Comunidad Industrial llegase a ser prop:etaria del cincuenta por ciento $(50 \%)$ del capital social, instaurándose una auténtica copropiedad empresarial.

De la misma manera, la participación en la gestión alcanzaría semejante proporción, estableciéndose una cogestión en la empresa.

Este sistema de participaciōn, con algunas variantes prop:as de cada sector, se hizo luego extensivo a la actividad pesquera (Decreto Ley 18810), minera (Decreto Ley 18880) y telecomuni. caciones (Decreto Ley 19020). Sin embargo, no llegó a extender. se a sectores tan significativos como la banca y finanzas, y el comercic, que continuaron aplicando el régimen de la ley 11672

A partir del año 1977, comenzando asimismo por el sector industrial y extendiéndose posteriormente a la pesqueria y la mineria, pero no a las telecomunicaciones (80) por su régimen peculiar, este sistema fue sustancialmente modificado, por uno en el que se reemplazó la participación en la propiedad empresarial mediante acciones comunes por una participación "en el patrimon"o", mediante los titulos denominados "acciones laborales", representativos de una cuenta patrimonial de participación distinta e independiente del capital social. Dicha participación no debe stiperar cifra equivalente al $50 \%$ del captal social, con lo cual, por ser cuenta aparte, la participación final sobre el patrimonio llegará como cifra tope al tercio de dicho patrimonio empresarial. En igual nedida, se afectó la participación en la gestión empresarial que por aplicación de estos criterios no podrá superar, en el mejor de lo: casos, el tercio del Directorio. En la Junta General, quedó suprinida toda participación laboral.

Hemos sostenido en otra oportunidad que "La acción laboral v'ene a constituir, en último análisis, una figura "sui generis" crea-

(@) En este sector, el Decreto Ley 19020 que instituyó la Comunidad Laboral no ctorgó a los trabajadores derecho sobre la propiedad de la empresa. 
da en circunstancias muy particulares, con una finalidad más politica que juridica, y que, en la práctica, introduce una trascendente reforma de la Comunidad Laboral que ha eliminado el acceso de los trabajadores a la propiedad empresarial" (81).

T'al era la situación de la participación de los trabajadores en là empresa cuando se aprobó la Constitución vigente, que recoge la institución en su artículo 56. El indicado artículo presenta, en cste sentido, dos párrafos de alcance diferente que conviene anali zar con algün detenimiento.

El primer párrafo afirma: "El Estado reconoce el derecho de los trabajadores a participar en la gestión y utilidad de la empresa, de acuerclo con la moḍal:dad de ésta". En nuestro concepto esta afirmación incluye dentro del ámbito del derecho a la participación laboral en las utilidades y la gestión, a todas las empresas, sin excepción alguna, permitiendo, únicamente, diferentes aplicaciones del derecho en consideración a las diversas modalidades existentes en la legislación. Las modalidades empresariales, a falta de algna definición en el texto constitucional, no pueden ser otras que las enumeradas en el artículo 112 de la Constitución, que en su sagundo párrafo sostiene que "Las empresas estatales, privadas, cooperativas, autogestionarias, comunales y de cualquier otra modalidad, actúan con la personería jurídica que la ley señala de acuerdo con sus caracteristicas".

En este sentido, todas las empresas alli mencionadas deben aplica: el principio del artículo 56, primer párrafo, entendiendose quie la norma es de validez particular en el caso de las empresas cstatales, privadas y las cooperativas de ustuarios, por cuanto las cooperativas de trabajadores y las empresas autogestionarias y comunales se organizan, precisamente, a base de una participación plena de sus trabajadores en todos sus niveles. En tal sentido, la legislación vigente que excluye a las pequeñas y medianas em-

(81) BLANCAS BUSTAMANTE, Carlos... La acción Laboral en el nuevo régimen de comunidad laboral en Apuntes, Lima, Centro de Investigación de la Universidad del Pacifico. Núm. 10, Año V, 1980, p. 68. 
presas de alguno o ambos niveles de participación resulta inconstitucional (82).

En cuanto al segundo párrafo, éste se refiere al derecho a participar en la propiedad estableciendo: "La participación de los trabajadores se extiende a la propiedad en las empresas cuya naturaleza jurídica no lo impide". En esta cuestión creemos que pase a su vaguedad, hasta cierto punto enigmática, el párrafo segundo del artículo 56 se reficre al régimen de propiedad de la empresa, es decir, a la naturaleza juridica del régimen de propiedad sobre el cual se organiza la empresa. Sólo así, podria comprenderse que en algunos casos dicho régimen de propiedad excluya la participación por cuanto de darse ésta se modificaría su naturaleza juridica. Opinamos que éste seria el caso de la empresa de propiedad estatal, en la cual si hubiese participación laboral en la propiedad - que sería un derecho privado de los trabajadoresla empresa devendria mixta; o el caso de la empresa de propiedad individual (uni-personal o empresa individual de responsabilidad limitada) en la cual la participación laboral en la propiedad la obligaria a transformarse en sociedad, cambiando su régimen individual de propiedad.

Ello, en cambio, no ocurre en la empresa privada constituil como sociedad, ya que la participación de los trabajadores en la propiedad no variará la naturaleza de su régimen de propieciad, ya que se trataria únicamente de la incorporación de uno o más socios. En cuanto a las empresas cooperativas de trabajadores, autogest:onarias y comunales, ellas no presentan dificultad alguna respecto a este derecho porque se basan en la propiedad de los trabajadores sobre la empresa.

De lo expuesto, concluimos que las empresas privadas qure no sean pequeña empresa de propiedad individual, deben tener un régimen de participación de los trabajadores en la propiedad. Este nivel de participación lo entendemos como derecho sobre el capital social de la empresa, tal como se concibe en la doctrina

(82) Nos referimos al Decreto Ley No 23189 y a la reciente Ley General de Industrias, Ley 23407, que no establecen participación laboral en la gestión de las pequeñas empresas. 
jurídica de las sociedades y en nuestra legislación sobre la materia, que atribuyen a los accionistas de la empresa la condición de sccios, con plenitud de derechos patrimoniales y de gesiiôn respecto de la empresa.

Por ello, tienen razón Rubio y Bernales cuando estinian, refiriéndose a la legislación que ha creado el sistema de acciones laborales en sustitución de la participación mediante acciones comunes, que "...es evidente que las nuevas leyes eliminan la propiedad real de los trabajadores sobre las empresas, al negar la propiedad sobre el capital" (83). Por nuestra parte, hemos sostenido que "...se puede apreciar que la denominada "acción laboral", si bien presenta ciertas similitudes con la acción no reúne la plenitud de las caracteristicas esenciales que, a juicio de la doctrina, definen el concepto de acción. En tal sentido, consideramos perfectamente válido sostener que la "acción laboral" no es, juridicamente, acción" (84).

La consecuencia práctica del artículo 56 , en su segundo párrafo es, a nuestro juicio, doble: por un lado, debe modificarse la legislación vigente en materia de Comunidad Laboral a fin de establecer un rég:men de participación que otorgue a los trabajadores efectiva participación en la propiedad del capital de las empresas privadas, y de otro lado, debe extenderse el régimen de partcipación en utilidades, gestión y propiedad hacia las sectores de la actividad económica que carecen de tal régimen porque así lo manda la Constitución.

La nueva Ley General de Industrias, dictada recientemente bajo el número 23407 no significa, en este campo, prog̣reso alguno, sino, por el contrario, un serio retroceso. Ofrece a los tria bajadores un doble sistema de participación patrimonial y en utilidades: el primero es virtualmente igual al que está vigente y que hemos criticado linea arriba, y el segundo implica dejar de lado ese régimen para que los trabajadores reciban a cambio una part:cipación liquida mayor que la actual, esto es, el $17 \%$ de la renta ncta, antes de impuestos, en lugar del 10\%. Se elimina el

(83) RLBIO, Marcial y BERNALES, Enrique, op. cit., p. 589.

(84) BLANCAS, Carlos, La acción laboral..., op. cit., p. 67. 
sistema de participación patrimonial mediante acciones laborales $y$ en su lugar se concede a los trabajadores una opción preferencial para suscribir, en caso de aumento de capital por suscripción pública, no menos del $10 \%$ de dicho aumento. Este aparente beneficio o derecho no es tal porque,, como sabemos, ya se encuentra previsto en la Ley de Sociedades Mercantiles, toda vez que tratándose de "suscripción pública" cualquiera del público, :nclu1dos los trabajadores de la empresa, puede suscribir acciones, por lo que no se trata de un derecho "creado" por la Ley General de Industrias. La opción preferencial sobre el $10 \%$ no es más que una facilidad para el ejercicio de un derecho de carácter general y mercantil y no laboral como el de suscrib:r acciones por oferta pública. Por otro lado, este mecanismo de la suscripción pública es virtualmente inexistente en el Perú como medio de hacer efectivo un aumento de capital $\mathrm{y}$, en todo caso, su realización depende de un acuerdo, con quórum especial y mayoría calificada, de la Junta de Accionistas, a la cual no tienen acceso los trabajadores. Cabe decir, finalmente, que se trata de una opción para la cual la ley no preve ningún tipo de financiamiento o recurso que permita a los trabajadores hacerla efectiva, por lo que se convierte en una opción des:gual para los trabajadores, desvinculada por completo de su participación en la generación de !a renta empresarial, y librada, exclusivamente, a la capacidad económica individual o familiar de cada trabajador.

En consecuencia, no se trata, realmente, de una apl:cación ca. bal del artículo 56 de la Constitución, que hace referencia a un derecho de los trabajadores, intimamente vinculado al precepto contenido en los artículos 42 y 110 , según el cual el trabajo es la "fuente principal de la riqueza". 